\title{
Operative Time and Complication Rates of Resident Phacoemulsification Surgeries in a National University Hospital: A Five-Year Review
}

This article was published in the following Dove Press journal:

Clinical Ophthalmology

\section{Maria Isabel N Umali $(\mathbb{D}$ \\ Teresita R Castillo}

Department of Ophthalmology and Visual Sciences, University of the Philippines Manila, Philippine General Hospital, Manila, Philippines
Correspondence: Maria Isabel N Umali Asian Eye Institute, $8^{\text {th }}$ Floor, Phinma Plaza Building, Hidalgo Drive, Makati City, Philippines

Tel +639175390045

Email isabelumali.md@gmail.com
Purpose: To determine the operative time and complication rates of resident phacoemulsification surgeries at different time points in training.

Methods: Retrospective cross-sectional study at the Department of Ophthalmology of the Philippine General Hospital. All resident-performed elective adult phacoemulsification surgeries from January 1, 2014, to December 31, 2018, were included, while operations with planned anterior or posterior procedures were excluded. Cases were arranged chronologically and divided into time points with 25 cases each. Operative time and complication rates were computed for each time point. As defined by the ICO Ophthalmology Surgical Competency Assessment Rubric (OSCAR), 30 minutes was used to gauge competency based on operative time, while complications were compared to published rates for residents. Results for the first 50 cases, the minimum number required by graduation, were also compared with succeeding cases.

Results: A total of 4635 cases were included. Residents performed an average of $115.9 \pm$ 30.4 cases, with no significant difference among residents $(F(4,35)=2.64, \mathrm{p}=0.12)$. Overall complication rate was $6 \%(n=276)$, similar to those reported internationally. Both median operative time and complication rates decreased significantly for every time point in training $(\mathrm{p}<0.001)$. After 50 cases, only $40 \%(n=16)$ of residents reached the operative time of 30 minutes. Median operative time is significantly lower when comparing the first 50 surgeries with the succeeding cases ( 37 minutes vs 29 minutes, $p<0.001$ ). Likewise, complication rate is also significantly lower $\left(9.3 \%\right.$ vs $\left.3.5 \%, \mathrm{X}^{2}(1, \mathrm{~N}=4635)=68.481, \mathrm{p}<0.001\right)$, with an odds ratio of 2.85 ( $\mathrm{p}<0.001,95 \%$ CI $[2.2,3.7])$.

Conclusion: There are significant improvements in both operative time and complication rates as more surgeries are performed. However, the minimum required 50 cases is not enough for resident competency based on operative time and complication rates.

Keywords: resident training, learning curve, cataract surgery, assessment

\section{Introduction}

Cataract is the leading cause of reversible blindness worldwide ${ }^{1}$ with a national prevalence of $62 \% .^{2}$ Thus, learning and mastering phacoemulsification, a safe and cost-effective type of cataract surgery, ${ }^{3}$ is an integral part of residency training. Numerous studies have sought to measure the learning curve in resident surgeries using parameters such as operative time,${ }^{4-8}$ intraoperative complications, ${ }^{8-14}$ direct 
supervisor interventions, ${ }^{9,10}$ visual outcomes, ${ }^{8,14,15}$ and return to the operating room. ${ }^{16,17}$ These studies demonstrated that increased surgeon experience corresponded to a decrease in these parameters. In a chart review of 680 cases, the adjusted phacoemulsification time and vitreous loss rate were significantly decreased when comparing the first 80 cataract surgeries of residents with the 81st to 207th surgeries. ${ }^{8}$ In another study, resident operative times decreased $25 \%$ from the 45 th to the 86 th case and $9 \%$ from the 86 th to the 121 st $^{\text {case. }}{ }^{4}$ Many studies on resident performed phacoemulsification surgeries have also reported varying complication rates. ${ }^{9,12,14,18-21}$

Countries have different requirements as to the number of phacoemulsification surgeries required per resident upon graduation. In the United States, the Accreditation Council for Graduate Medical Education requires a total of 86 cases. ${ }^{22}$ In the United Kingdom, the Royal College of Ophthalmologists requires 50 cases completed by residents over the first two years and 350 cases over seven years of training. ${ }^{23}$ In the country, the Philippine Board of Ophthalmology requires a minimum of 50 surgeries upon the end of a three-year residency program, with phacoemulsification usually performed during the last year. A retrospective records review of 492 cases done locally showed significant improvement in phacoemulsification time and complication rates with an increasing number of cases. ${ }^{24}$ However, this study only analyzed one batch of residents.

This research sought to measure the operative time and intraoperative complication rates of resident performed phacoemulsification surgeries in a public tertiary training institution for five consecutive years. Results were then compared to the accepted surgery duration based on the International Council of Ophthalmology (ICO) Ophthalmology Surgery Competency Assessment Rubric (OSCAR) and published international data on resident intraoperative complication rates for phacoemulsification.

\section{Materials and Methods}

This is a retrospective cross-sectional study of all phacoemulsification cases done by five consecutive batches ( 40 third-year residents) at the Department of Ophthalmology of the Philippine General Hospital, the largest public tertiary training institution in the country.

\section{Ethical Considerations}

Approval was obtained before the conduct of the study from the institution's ethics review board, the University of the Philippines, Manila, Research Ethics Board (UPMREB). Since this study was a records review and did not introduce any intervention, a waiver of informed consent was obtained and granted by the review board. All patients who underwent surgery have given consent for their respective surgeries. This study was done in accordance with the Declaration of Helsinki. No patient identifiers were collected, and the resident names and batches were codified and anonymized.

\section{Data Collection and Analysis}

The operating room nurses' logbook for elective surgeries from January 1, 2014, until December 31, 2018, were retrieved and reviewed. All elective phacoemulsification surgeries done by all third-year residents for the year were included, while surgeries with planned anterior or posterior procedures such as limbal relaxing incisions, goniosynechiolysis, intravitreal injections, or pars plana vitrectomies were excluded. Only surgeries using local anesthesia were included in this study. Surgeries with a preoperative diagnosis of complicated cataracts, such as intumescent cataract, were excluded. The date, procedure, surgeon, time start, and time end of surgery were collected and manually encoded in an electronic spreadsheet (Excel 2016). Encoded data were rechecked for accuracy by the investigators before analysis.

Cases were categorized per resident and numbered chronologically. The cases were then arbitrarily divided into segments with 25 cases, each representing points in the residents' learning curve (ie, time point one- 1st-25th cases, time point two- 26th-50th cases). Cases over 100 were grouped as time point five. Mean and median operative time and complication rates were determined for each time point.

Total operative time was defined as the difference in the recorded procedure start and end times in minutes. More specifically, nurses record the start time at surgical time-out, just as the surgeon starts the surgery in the operating room. The end time is recorded when the lid retractors are removed, and eye protection/dressing is placed. Intraoperative complications were noted as the unplanned procedures done to address complications during the same sitting. These include anterior vitrectomy, sulcus intraocular lens (IOL) implantation, non-placement of IOL, and phacofragmentation.

\section{Surgical Training and Methods}

The hospital's phacoemulsification cases are assigned to fellows and third-year residents; however, this research 
only included cases done by residents. As early as their first year of training, residents can assist and observe multiple surgeries, but there is no required number of assisted or observed cases before starting phacoemulsification. Residents are trained through wet labs (using pig eyes), lectures, and video-conferences. At present, there are no eye surgery simulators in the department. During the first months of surgical training, residents operate with attending surgeons who assess their surgical skills using the ICO-OSCAR. The training is through the performance of the whole surgery instead of the stepwise approach. Mastery of individual steps is not required before starting the other steps. Attendings can take over the surgery at any point they deem necessary and feedback is given right after surgery. To be "certified" to perform surgeries without an attending assist, residents must garner a rating of 4/ 5 (advanced beginner) or 5/5 (competent) from at least five completed surgeries assisted by attendings. Usually, most residents are already certified to do surgeries without direct attending supervision by their 15 th case. For their next cases, they are assisted by fellows or co-residents. In cases wherein intraoperative complications happen, another co-resident, fellow, or attending can be called. Depending on their availability, fellows and attendings scrub in to assist; if not, instructions are given verbally. Most of the time, residents handle the complications and finish the case themselves. An exception would be cases needing surgical retina intervention such as phacofragmentation, wherein the surgical retina fellow finishes the surgery. This research examined the surgical learning curves of forty consecutive third-year residents. Information on the number of cases that were assisted and taken over by attendings are not available.

A general walkthrough of the department's surgical procedure is as follows: The patient is wheeled into the operating room and transferred to the operating table. Oxygen support and monitoring equipment are attached, while patient identity, intraocular lens power, and other surgery details are checked and confirmed by the nurses. The surgeon focuses the microscope and gives some final preoperative advice to the patient. While the surgeon and assist are scrubbing, another resident prepares the patient aseptically, after which the scrub nurse drapes the patient. The surgeon and the assist are then scrubbed in and position themselves in the operative field. The nurse does the "time-out" with the surgical team. The surgeon does the Povidone Iodine lid scrub and places the lid retractors on the patient.
Manual phacoemulsification surgery is done, with corneal incisions made using single-use ophthalmic knives. Utrata forceps is used to create a continuous curvilinear capsulorhexis. Nuclear fragmentation is done through various techniques. Most common are the "stop-and-chop" and "divide-and-conquer", though some may also do the "quickchop". The Verges chopper is used for these horizontal chopping methods. Different machines were also utilized during the period encompassed by the study. These included the Alcon Infiniti (Alcon, Fort Worth, Texas, USA), Geuder megaTRON S4 HPS (Geuder, Heidelberg, Germany), Zeiss Visalis V500 (Carl Zeiss Meditec AG, Jena, Germany), and Oertli Faros (Oertli, Berneck, Switzerland) phacoemulsification machines using a 20-gauge phacoemulsification needle. The irrigation and aspiration step is done using a coaxial tip, but some residents also practice the bimanual technique.

The intraocular lens (IOL) is only opened once advised by the surgeon, usually at the end of irrigation and aspiration. Most IOLs are manually loaded by the nurses. After viscoelastic removal and polishing, intracameral antibiotics are injected. Corneal incisions are closed through stromal hydration unless a Nylon 10-0 sutured incision is warranted. After the final check, retractors are removed, and antibiotic and steroid drops and eye protection is placed. The patient is then wheeled out of the operating room and into the patient waiting area. Details on the types of machine, nuclear fragmentation techniques, intraocular lens loading practices, and irrigation and aspiration styles were not recorded. Due to this research's retrospective nature, differences in operative time and complication rates due to these factors are not within this study's scope.

\section{Statistical Analysis}

Study variables were presented as frequency distributions, means $\pm \mathrm{SD}$ or medians and interquartile ranges. Training segments were stratified arbitrarily into 25 cases, each as earlier described. Independent $T$-tests, one-way ANOVA/ Kruskal-Wallis H (median), and Pearson Chi-Square tests were used to determine statistical differences between groups. All analyses were conducted using SPSS version 26 for Windows (IBM Corp, Armonk NY), and an alpha level $\mathrm{p}<0.05$ was used to determine significance.

\section{Results}

A total of 4635 phacoemulsification cases fulfilling both inclusion and exclusion criteria were included. Residents performed an average of 115.9 cases $( \pm 30.4)$. There was no significant difference in the mean number of cases per resident 
among the different batches $(F(4,35)=2.64, \mathrm{p}=0.12)$ (Table 1).

\section{Operative Time}

The median operative time was used as the measure of central tendency due to outliers on initial analysis. Overall operative times were computed (Table 2) and were noted to be significantly different $(\mathrm{p}<0.001)$ among all time points, except for time points four and five (76th case onwards). When computed for each batch, operative time decreased for every time point in training. Median operative time was also significantly increased for the first fifty cases (37 minutes, $\mathrm{IQR}=21$ ) compared to the following cases (29 minutes, $\mathrm{IQR}=13, \mathrm{U}=1,655,427, \mathrm{n}=4635, \mathrm{p}<0.001$ ).

Results of individual residents showed that the median operative time of 45 minutes or less was achieved by the majority $(78 \%, n=31)$ of residents during time point one ( $1 \mathrm{st}-25$ th cases), the time residents get certified to do surgeries without direct attending assistance. However, only $40 \%(\mathrm{n}=16)$ reached thirty minutes at time point two (26th-50th cases), the point corresponding to the minimum required fifty cases by graduation. Most residents $(58 \%, \mathrm{n}=23)$ reached the thirty-minute median operative time at time point three $(51 \mathrm{st}-75$ th cases), while $75 \%(n=30)$ reached it by time point four (76th-100th cases).

\section{Intraoperative Complication Rate}

The complication rate was measured indirectly using a secondary outcome, unplanned procedures done to address complications that arose during the same sitting. From the 4635 cases analyzed, 4359 cases (94\%) were uneventful (mean operating time $35 \pm 17$ minutes), and 276 cases (6.0\%) had unplanned procedures done (mean operating time $88 \pm 39$ minutes). The most common procedure was anterior vitrectomy ( $\mathrm{n}=112,2.4 \%)$, followed by sulcus intraocular lens placement $(n=71,1.5 \%)$, non-placement of intraocular lens $(n=49,1.1 \%)$ and phacofragmentation $(n=37$, $0.8 \%$ ). Other procedures, such as insertion of a capsular tension ring and conversion to large incision extracapsular cataract extraction, account for $0.2 \%$ of cases $(n=7)$ (Table 3).

Complication rates were highest during the first 25 cases at $12.3 \%(\mathrm{n}=123)$, then decreased after (Table 4). Among all residents, $40 \%(\mathrm{n}=16)$ had complication rates higher than the overall rate of $6 \%$. Furthermore, the $15 \%(n=6)$ of residents who did not reach the 30-minute median operative time during training also had an increased average overall complication rate of $8.85 \%$.

The complication rate for the first 50 surgeries is significantly higher $(9.3 \%, \mathrm{n}=185$ out of 2000 cases $)$ than in succeeding surgeries $(3.5 \%, \mathrm{n}=91$ out of 2635 cases $),\left(\mathrm{X}^{2}(1\right.$, $\mathrm{N}=4635)=68.481, \mathrm{p}<0.001)$, with $80 \%$ of residents $(\mathrm{n}=32)$

Table I Average \pm SD and Total Phacoemulsification Surgeries Done by Third-Year Residents for the Past Five Years (Batches are Anonymized)

\begin{tabular}{|l|l|l|l|l|l|l|l|}
\hline Batch (Total) & A (N=845) & B (N=86 I) & C (N=9 I5) & $\mathbf{D ~ ( N = 8 8 7 ) ~}$ & E (N=I I 27) & Total (N=4635) & P-value \\
\hline $\begin{array}{l}\text { Average } \\
\pm S D\end{array}$ & 105.6 & 107.6 & 114.4 & 110.9 & 140.9 & 115.9 & 0.12 \\
\pm 36.0 & \pm 21.4 & \pm 21.5 & \pm 15.6 & \pm 42.0 & \pm 30.4 & \\
\hline
\end{tabular}

Abbreviation: SD, standard deviation.

Table 2 Median Operative Time in Minutes for Time Point in Training

\begin{tabular}{|c|c|c|c|c|c|}
\hline \multirow[t]{2}{*}{ Batch } & \multicolumn{5}{|c|}{ Median Operative Time (Minutes) Per Time Point (Case Sequence) } \\
\hline & I (I-25) N=1000 & $2(26-50) N=1000$ & $3(5 \mathrm{I}-75) \mathrm{N}=963$ & $4(76-100) N=821$ & 5 ( 101 Onwards) $N=853$ \\
\hline A & 43 & 35 & 30 & 27 & 24 \\
\hline B & 43 & 34 & 32 & 30 & 25 \\
\hline C & 45 & 36 & 33 & 30 & 27 \\
\hline D & 42 & 30 & 29 & 25 & 30 \\
\hline $\mathrm{E}$ & 40 & 30 & 29 & 30 & 27 \\
\hline Overall (IQR) & $42(26)$ & $33(18)$ & $30(15)$ & $28(12)$ & $27(14)$ \\
\hline (Lower, Upper Hinges) & $(32,58)$ & $(26,44)$ & $(24,39)$ & $(23,35)$ & $(21,35)$ \\
\hline
\end{tabular}


Table 3 Complication Rate and Frequency of Procedures Done to Address Intraoperative Complications per Batch

\begin{tabular}{|l|l|l|l|l|l|l|}
\hline \multirow{2}{*}{ Unplanned Procedure } & \multicolumn{3}{|l|}{ Batch } & \multicolumn{3}{|l|}{ Total } \\
\cline { 2 - 7 } & A & B & C & D & E \\
\hline Sulcus IOL implantation & $20(2.4 \%)$ & $20(2.3 \%)$ & $15(1.6 \%)$ & $7(0.8 \%)$ & $9(0.8 \%)$ & $71(1.5 \%)$ \\
Anterior vitrectomy & $15(1.8 \%)$ & $30(3.5 \%)$ & $13(1.4 \%)$ & $23(2.6 \%)$ & $31(2.8 \%)$ & $112(2.4 \%)$ \\
Non-placement of IOL & $5(0.6 \%)$ & $10(1.2 \%)$ & $8(0.9 \%)$ & $13(1.5 \%)$ & $13(1.2 \%)$ & $49(1.1 \%)$ \\
Phaco-fragmentation & $3(0.4 \%)$ & $6(0.7 \%)$ & $8(0.9 \%)$ & $13(1.5 \%)$ & $7(0.6 \%)$ & $37(0.8 \%)$ \\
Others & $1(0.1 \%)$ & $3(0.3 \%)$ & $0(0 \%)$ & $1(0.1 \%)$ & $2(0.2 \%)$ & $7(0.2 \%)$ \\
Total $^{\mathrm{a}}$ & $44(5.2 \%)$ & $69(8.0 \%)$ & $45(4.9 \%)$ & $57(6.4 \%)$ & $61(5.4 \%)$ & $276(6.0 \%)$ \\
\hline
\end{tabular}

Note: ${ }^{a}$ Includes insertion of capsular tension ring, conversion to large incision extracapsular cataract extraction.

Abbreviation: IOL, intraocular lens.

Table 4 Complication Rate and Frequency of Procedures Done to Address Intraoperative Complications per Time Point in Training

\begin{tabular}{|c|c|c|c|c|c|}
\hline \multirow[t]{2}{*}{ Unplanned Procedure } & \multicolumn{5}{|c|}{ Time Point in Training (Case Sequence) } \\
\hline & $I(1-25)$ & $2(26-50)$ & $3(5 I-75)$ & $4(76-100)$ & 5 ( 101 Onwards) \\
\hline Sulcus IOL implantation & 40 & 11 & 13 & 4 & 3 \\
\hline Anterior vitrectomy & 46 & 30 & 14 & 10 & 12 \\
\hline Non-placement of IOL & 21 & 9 & 8 & 5 & 6 \\
\hline Phacofragmentation & 13 & 10 & 5 & 4 & 5 \\
\hline Others $^{\mathrm{a}}$ & 3 & 2 & 1 & I & 0 \\
\hline Complication rate \% (Total) & $12.3 \%(123)^{\mathrm{b}}$ & $6.2 \%(62)^{b}$ & $4.3 \%(4 I)^{b}$ & $2.9 \%(24)$ & $3.0 \%(26)$ \\
\hline
\end{tabular}

Notes: ancludes insertion of capsular tension ring, conversion to large incision extracapsular cataract extraction. ${ }^{b}$ Proportions differ significantly from each other $(p<0.05)$. Abbreviation: IOL, intraocular lens.

showing a significant decrease in their complication rates for these two time points. Complication rates increased in $20 \%$ $(n=8)$ after their 50th surgeries, but these were not statistically significant from their previous complication rates. Likewise, $20 \%(n=8)$ had consistently higher than average complication rates for the first 50 surgeries and onwards. Lastly, the odds of having a complication during the first 50 phacoemulsification cases is 2.85 times higher compared to succeeding surgeries $(p<0.001,95 \%$ CI $[2.2,3.7])$.

\section{Discussion}

Results showed a decrease in mean and median operative time as the number of surgeries performed by each resident increased. This finding is similar in many previous studies. For instance, in a retrospective study of 1904 cases in Manchester Royal Eye Hospital, the mean surgical training time decreased from $27.63 \pm 12.57$ minutes for 1- to 3-year trainees to $22.55 \pm 11.90$ minutes for 4 - to 7 -year trainees. ${ }^{25}$ Aside from years in training and surgeon grade, a study at Epsom and St. Helier University National Health Service Trust in London examined factors which significantly affected cataract surgery operating time such as anesthesia type, case complexity, pupil size, pupil expander use, capsular tension ring use and presence of intraoperative complications. ${ }^{26}$

The ICO-OSCAR, a standardized internationally valid tool to teach and assess an ophthalmologist's competence in performing surgery, is applied by the Philippine Board of Ophthalmology (PBO) for the assessment of residents' phacoemulsification surgeries. The last criterion of the ICOOSCAR is overall speed and fluidity, with the highest score (score 5/5) being described in the following statement: "inefficient and unnecessary manipulations are avoided. Thirty minutes should be adequate"... ${ }^{27}$ Likewise, the ICOOSCAR also described the estimated operative times for the other levels of surgical competency. Novice level (score 2/5) had a case duration of more than one hour, beginner level (score 3/5) had 60 minutes, advanced beginner (score 4/5) had 45 minutes, and the competent level (5/5) had 30 minutes. Thus, for this research, 30 minutes was used as the acceptable operative time to gauge surgeon competency.

As mentioned previously in the Surgical Techniques and Training section, "certification" is achieved with five OSCAR ratings of either 4/5 (advanced beginner) to $5 / 5$ (competent), which in turn corresponds to a case duration of 45 and 30 minutes, respectively. This practice 
corresponded with the results, wherein most of the residents achieved a median case duration of 45 minutes or less by the end of their 25 cases, the time point when all residents have already been "certified." Although most have reached the "advanced beginner" level by time point 1 in operative time, the learning curve differed among residents afterward. Many residents were still unable to reach the "competent" level by their 50th case, with $75 \%$ reaching this only by the 76 th case.

Multiple reasons can be used to explain this observation. Since after 25 cases, usually all residents are already certified and not anymore directly assisted by attendings during the surgery, they may have been more cautious in their movements. Simultaneously, the difficulties and complications encountered during surgery were handled by the residents, having no attending to take-over, in contrast to the early part of training wherein more hand-holding was involved. Unfortunately, data on the number of surgeries that were finished or taken-over by attendings are not available.

This study also showed that all five batches only reached this thirty-minute standard of competence at time point four (76th-100th cases). Data from individual residents also showed that $75 \%$ reached thirty minutes, also at time point four. These results prove that the minimum required fifty cases by the end of training is not enough to achieve the "competent" ICO- OSCAR standard in terms of operative time.

Furthermore, there was a significant difference in operative time for all time points in training except for time points four and five (76th case onwards). This finding mirrors the results of a retrospective review of 375 cases from the University of Arkansas, reporting smaller decreases after the 86 th surgery. ${ }^{4}$ This finding points to a plateau in the general learning curve of the residents.

Over-all intraoperative complication rate $(6 \%)$ parallels that obtained earlier from the same institution $(6.7 \%){ }^{24}$ Reported complication rates for resident surgeries in various training institutions ranged from around $1.8-11.2 \%{ }^{28}$ As with operative time, complications also decreased with an increasing number of surgeries done. Complication rates were compared between the first 50 and the following surgeries because this marked the minimum requirement by graduation. Findings showed a significant difference between these two time points. At the same time, the majority of residents had decreased complication rates after 50 cases. Thus, increasing the number of required cases should be considered since significant improvements still occur after.

The odds of having a complication are high for the first fifty cases. A study found that the rate of complications by resident performed surgeries falls by $50 \%$ after the first 40 cases. $^{29}$ In a retrospective study of 680 cases in Atlanta Veterans Affairs (VA) Medical Center, a complication rate of $5 \%$ with a significant decrease in complications by the 80th case was reported. ${ }^{8}$ Similarly, another review of 1442 cases at the Nashville VA Hospital showed a statistically significant decrease in intraoperative complications once the surgeon had performed 80 surgeries. ${ }^{30}$ These results corroborate this study showing a plateau in complication rates at 76th surgery onwards.

Although not statistically significant, several residents had increased complication rates towards the end of their training. Exact reasons for this are not part of the study but may include surgeon factors such as complacency and overconfidence or surgical factors such as more complicated cases. However, data on case difficulty and correlation with complication rate and operative time were not analyzed in this study. Remarkably, some residents consistently had increased complication rates. These residents may have had other personal limitations, such as poor hand-eye-leg coordination or problems with stereopsis. Thus, trainers should closely monitor each resident's complications, if possible, from a non-selfreported source and determine early on any difficulty or weakness, which may affect their learning curve and hinder their improvement. Doing so will not only help the resident improve but also provide better patient outcomes.

Many studies sought to describe the resident learning curve for phacoemulsification surgery. ${ }^{8,31-35}$ Complication rates of residents from other countries such as Turkey $(10.1-23.3 \%),{ }^{9}$ Croatia $(15.12 \%),{ }^{18}$ Iran $(9.6 \%),{ }^{19}$ India $(7.1-37 \%),{ }^{21,36}$ Germany $(3.8 \%),{ }^{31}$ Brazil (7.6-11.4\%), ${ }^{37,38}$ Thailand (6.9\% vitreous loss only) ${ }^{39}$ and Malaysia $(6.9 \%)^{40}$ have also been published. This study's results are comparable to the rates reported, notably those from neighboring Southeast Asian countries.

Phacoemulsification in the country is traditionally done only during the third year of residency, while extracapsular cataract extraction (ECCE) is done during the second year. Because this research shows that performing more cases translates to better operative time and lower complication rates, this surgery can be introduced earlier. In most training programs in the United States, residents begin performing phacoemulsification in the first two years of residency, with no required ECCE surgeries before starting 
phacoemulsification. This early introduction has also been shown to decrease intraoperative complication rates significantly. 41

The use of various surgical simulators has shown promising results in hastening residents' learning curve in phacoemulsification. ${ }^{42-44}$ In the UK database study of 17,831 cataract surgeries done by first and second-year residents, there was a $38 \%$ reduction in posterior capsular rent $(4.2 \%$ in 2009 vs $2.6 \%$ in 2015) for surgeons with access to an EyeSi simulator. In contrast, there was only a $3 \%$ reduction $(2.9 \%$ in 2009 vs $2.8 \%$ in 2015$)$ for surgeons without access. ${ }^{44}$ In a comparative case series analyzing 592 cases, shorter phacoemulsification time, lower percentage power, fewer intraoperative complications, and a shorter learning curve were observed in residents who trained using the simulator. ${ }^{45}$

Due to the study's retrospective nature, data on cataract grading, case difficulty, specific surgical technique or machine used, and postoperative outcomes are unknown. Likewise, the reported intraoperative complication rate may be falsely low, for instance, in cases wherein phacofragmentation was not done in the same sitting. Furthermore, the study relied on logbooks wherein data collection may not be uniform. Nonetheless, this is the most extensive study describing residents' learning curve for phacoemulsification surgery in the country.

\section{Conclusion}

This study showed that though with significant improvement, residents are not yet competent phacoemulsification surgeons at fifty cases, the minimum required number of surgeries at the end of training, based on operative time and intraoperative complication rates. Methods to hasten the learning curve, such as the early introduction of surgeries and simulators, may be implemented. Analysis of learning curves from other institutions and review of the minimum surgical requirement in the country is also suggested.

\section{Acknowledgment}

Eliza Poareo, MD, for help in statistical analysis.

\section{Disclosure}

The authors report no conflicts of interest in this work.

\section{References}

1. Pascolini D, Mariotti SP. Global estimates of visual impairment: 2010. Br J Ophthalmol. 2012;96(5):614-618. doi:10.1136/bjophthalmol2011-300539
2. Cubillan LD, Olivar-Santos EO. Third national survey on blindness. Philipp J Ophthalmol. 2005;30(3):100-114.

3. Clark A, Morlet N, Ng JQ, Preen DB, Semmens JB. Whole population trends in complications of cataract surgery over 22 years in Western Australia. Ophthalmology. 2011;118(6):1055-1061. doi:10.1016/j.ophtha.2010.11.001

4. Wiggins MN, Warner DB. Resident physician operative times during cataract surgery. Ophthalmic Surg Lasers Imaging. 2010;41 (5):518-522. doi:10.3928/15428877-20100726-07

5. Taravella MJ, Davidson R, Erlanger M, Guiton G, Gregory D. Characterizing the learning curve in phacoemulsification. $J$ Cataract Refract Surg. 2011;37(6):1069-1075. doi:10.1016/j.jcrs.2010.12.054

6. Taravella MJ, Davidson R, Erlanger M, Guiton G, Gregory D. Time and cost of teaching cataract surgery. $J$ Cataract Refract Surg. 2014;40(2):212-216. doi:10.1016/j.jcrs.2013.07.045

7. Hosler MR, Scott IU, Kunselman AR, Wolford KR, Oltra EZ, Murray WB. Impact of resident participation in cataract surgery on operative time and cost. Ophthalmology. 2012;119(1):95-98. doi:10.1016/j.ophtha.2011.06.026

8. Randleman JB, Wolfe JD, Woodward M, Lynn MJ, Cherwek DH, Srivastava SK. The resident surgeon phacoemulsification learning curve. Arch Ophthalmol. 2007;125(9):1215. doi:10.1001/archopht.125.9.1215

9. Mangan MS, Atalay E, Arici C, Tuncer İ, Bilgeç MD. Comparison of different types of complications in the phacoemulsification surgery learning curve according to number of operations performed. Turk Patoloji Derg. 2016;46(1):7-10. doi:10.4274/tjo.83788

10. Lee JS, Hou CH, Yang ML, Kuo JZC, Lin KK. A different approach to assess resident phacoemulsification learning curve: analysis of both completion and complication rates. Eye. 2009;23(3):683-687. doi:10.1038/sj.eye. 6703103

11. Rutar T, Porco TC, Naseri A. Risk factors for intraoperative complications in resident-performed phacoemulsification surgery. Ophthalmology. 2009;116(3):431-436. doi:10.1016/j.ophtha.2008.10.028

12. Bhagat N, Nissirios N, Potdevin L, et al. Complications in resident-performed phacoemulsification cataract surgery at New Jersey medical school. Br J Ophthalmol. 2007;91(10):1315-1317. doi:10.1136/bjo.2006.111971

13. Woodfield AS, Gower EW, Cassard SD, Ramanthan S. Intraoperative phacoemulsification complication rates of second- and third-year ophthalmology residents: a 5-year comparison. Ophthalmology. 2011;118(5):954-958. doi:10.1016/j.ophtha.2010.08.047

14. Payal AR, Gonzalez-Gonzalez LA, Chen X, et al. Outcomes of cataract surgery with residents as primary surgeons in the Veterans Affairs healthcare system. J Cataract Refract Surg. 2016;42 (3):370-384. doi:10.1016/j.jcrs.2015.11.041

15. Blomquist PH, Morales ME, Tong L, Ahn C. Risk factors for vitreous complications in resident-performed phacoemulsification surgery. $J$ Cataract Refract Surg. 2012;38(2):208-214. doi:10.1016/j. jcrs.2011.10.001

16. Schmidt CM, Sundararajan M, Biggerstaff KS, Orengo-Nania S, Coffee RE, Khandelwal SS. Indications and outcomes of resident-performed cataract surgery requiring return to the operating room. J Cataract Refract Surg. 2016;42(3):385-391. doi:10.1016/j. jcrs.2015.11.043

17. Menda SA, Driver TH, Neiman AE, Blumberg S, Naseri A, Stewart JM. Risk factors for return to the operating room after resident-performed cataract surgery. Semin Ophthalmol. 2018;33 (2):210-214. doi:10.1080/08820538.2016.1208760

18. Lončar VL, Tadić R, Dujmović L, et al. The resident surgeon phacoemulsification learning curve at clinical department of ophthalmology, sestre milosrdnice university hospital center. Acta Clin Croat. 2016;55(4):549-554. doi:10.20471/acc.2016.55.04.03

19. Hashemi H, Mohammadpour M, Jabbarvand M, Nezamdoost Z, Ghadimi $H$. Incidence of and risk factors for vitreous loss in resident-performed phacoemulsification surgery. $J$ Cataract Refract Surg. 2013;39(9):1377-1382. doi:10.1016/j.jcrs.2013.03.028 
20. Low SAW, Braga-Mele R, Yan DB, El-Defrawy S. Intraoperative complication rates in cataract surgery performed by ophthalmology resident trainees compared to staff surgeons in a Canadian academic center. J Cataract Refract Surg. 2018;44(11):1344-1349. doi:10.1016/j.jcrs.2018.07.028

21. Lomi N, Sharma R, Khokhar S, Dada T, Vanathi M, Agarwal T. Risk factors for intra-operative complications during phacoemulsification performed by residents. Int Ophthalmol. 2016;36(3):401-406. doi: 10.1007/s10792-015-0146-7

22. ACGME. Required minimum number of procedures for graduating residents in ophthalmology. ACGME. 2013;2014.

23. The Royal College of Ophthalmologists. Grants Regist 2019. 2019:632-633. doi:10.1007/978-1-349-95810-8_1020

24. Kho RC, Villano MAD. Visual outcomes and intraoperative complication rates of phacoemulsification cataract surgery by third year ophthalmology residents in the up-philippine general hospital. Acta Med Philipp. 2019;53(4):350-354.

25. Park DY, Walkden A, De Klerk TA. Effect of cataract surgery training on operating room productivity: how long trainees take. $J$ Cataract Refract Surg. 2016;42(9):1297-1301. doi:10.1016/j. jcrs.2016.07.029

26. Nderitu P, Ursell P. Factors affecting cataract surgery operating time among trainees and consultants. J Cataract Refract Surg. 2019;45 (6):816-822. doi:10.1016/j.jcrs.2019.01.002

27. Golnik KC, Beaver H, Gauba V, et al. Cataract surgical skill assessment. Ophthalmology. 2011;118(2). doi:10.1016/j. ophtha.2010.09.023

28. Stein JD. Serious adverse events after cataract surgery. Curr Opin Ophthalmol. 2012;23(3):219-225. doi:10.1097/ICU.0b013e3283524 068

29. Ament CS, Henderson BA. Optimizing resident education in cataract surgery. Curr Opin Ophthalmol. 2011;22(1):64-67. doi:10.1097/ ICU.0b013e3283415040

30. Eisenstein D, Hu J. Evaluation of resident performed cataract surgery learning curve by complication rates. Invest Ophthalmol Vis Sci. 2010;51(13):5444

31. Briszi A, Prahs P, Hillenkamp J, Helbig H, Herrmann W. Complication rate and risk factors for intraoperative complications in resident-performed phacoemulsification surgery. Graefes Arch Clin Exp Ophthalmol. 2012;250(9):1315-1320. doi:10.1007/s00417-0122003-y

32. Yulan W, Yaohua S, Jinhua T, Min W. Step-by-step phacoemulsification training program for ophthalmology residents. Indian J Ophthalmol. 2013;61(11):659. doi:10.4103/0301-4738.120224

33. Kaplowitz K, Yazdanie M, Abazari A. A review of teaching methods and outcomes of resident phacoemulsification. Surv Ophthalmol. 2018;63(2):257-267. doi:10.1016/j.survophthal.2017.09.006
34. Rowden A, Krishna R. Resident cataract surgical training in United States residency programs. J Cataract Refract Surg. 2002;28 (12):2202-2205. doi:10.1016/S0886-3350(02)01380-9

35. El-Defrawy S. The resident surgeon phacoemulsification learning curve. Evid Based Ophthalmol. 2008. doi:10.1097/ IEB.0b013e31816c4256

36. Khanna RC, Kaza S, Shantha GPS, Sangwan VS. Comparative outcomes of manual small incision cataract surgery and phacoemulsification performed by ophthalmology trainees in a tertiary eye care hospital in India: a retrospective cohort design. BMJ Open. 2012;2 (5):e001035. doi:10.1136/bmjopen-2012-001035

37. Saad Filho R, Moreto R, Nakaghi RO, Haddad W, Coelho RP, Messias A. Costs and outcomes of phacoemulsification for cataracts performed by residents. Arq Bras Oftalmol. 2020;83(3):209-214. doi:10.5935/0004-2749.20200059

38. Carricondo PC, Fortes ACFM, Mourão PDC, Hajnal M, Jose NK. Senior resident phacoemulsification learning cure. Arq Bras Oftalmol. 2010;73(1):66-69. doi:10.1590/s0004-27492010000100012

39. Tayanithi P, Pungpapong K, Siramput P. Vitreous loss during phacoemulsification learning curve performed by third-year residents. J Med Assoc Thai. 2005.

40. Thevi T, Zin MM. Posterior capsule rupture-causes, associations and outcomes: eight year analysis in a Malaysian General Hospital. Int Eye Sci. 2016. doi:10.3980/j.issn.1672-5123.2016.4.03

41. Ellis EM, Lee JE, Saunders L, Haw WW, Granet DB, Heichel CW. Complication rates of resident-performed cataract surgery: impact of early introduction of cataract surgery training. $J$ Cataract Refract Surg. 2018;44(9):1109-1115. doi:10.1016/j.jcrs.2018.06.022

42. Lucas L, Schellini SA, Lottelli AC. Complications in the first 10 phacoemulsification cataract surgeries with and without prior simulator training. Arq Bras Oftalmol. 2019;82(4):289-294. doi:10.5935/ 0004-2749.20190057

43. Pokroy R, Du E, Alzaga A, et al. Impact of simulator training on resident cataract surgery. Graefes Arch Clin Exp Ophthalmol. 2013;251(3):777-781. doi:10.1007/s00417-012-2160-z

44. Ferris JD, Donachie PH, Johnston RL, Barnes B, Olaitan M, Sparrow JM. Royal college of ophthalmologists' national ophthalmology database study of cataract surgery: report 6 . the impact of eyesi virtual reality training on complications rates of cataract surgery performed by first and second year trainees. $\mathrm{Br} J$ Ophthalmol. 2020;104(3):324-329. doi:10.1136/bjophthalmol-2018-313817

45. Belyea DA, Brown SE, Rajjoub LZ. Influence of surgery simulator training on ophthalmology resident phacoemulsification performance. J Cataract Refract Surg. 2011;37(10):1756-1761. doi:10.1016/j. jers.2011.04.032
Clinical Ophthalmology

\section{Publish your work in this journal}

Clinical Ophthalmology is an international, peer-reviewed journal covering all subspecialties within ophthalmology. Key topics include: Optometry; Visual science; Pharmacology and drug therapy in eye diseases; Basic Sciences; Primary and Secondary eye care; Patient Safety and Quality of Care Improvements. This journal is indexed on PubMed
Central and CAS, and is the official journal of The Society of Clinical Ophthalmology (SCO). The manuscript management system is completely online and includes a very quick and fair peer-review system, which is all easy to use. Visit http://www.dovepress.com/ testimonials.php to read real quotes from published authors.

\section{Dovepress}

